\title{
Idiopathic macular telangiectasia type 1
}

INSERM

\section{Source}

INSERM. (1999). Orphanet: an online rare disease and orphan drug data base. Idiopathic macular telangiectasia type 1. ORPHA:353344

Idiopathic macular telangiectasia type 1 is a rare, acquired, eye disease characterized by unilateral (rarely bilateral) abnormally dilated and tortuous capillaries around the fovea, associated with multiple arteriolar and venular aneurysms, lipid depositions, and intraretinal cystoid degeneration. It leads to vision loss due to macular edema with hard exudates. 